\title{
z Why Right-Brain Teaching is Half-Witted: A Critique of the Misapplication of Neuroscience to Education
}

\author{
Annukka K. Lindell ${ }^{1}$ and Evan Kidd ${ }^{1,2}$
}

\begin{abstract}
Educational tools claiming to use "right-brain techniques" are increasingly shaping school curricula. By implying a strong scientific basis, such approaches appeal to educators who rightly believe that knowledge of the brain should guide curriculum development. However, the notion of hemisphericity (idea that people are "left-brained" or "right-brained") is a neuromyth that was debunked in the scientific literature 25 years ago. This article challenges the validity of "right-brain" teaching, highlighting the fact that neuroscientific research does not support its claims. Providing teachers with a basic understanding of neuroscience research as part of teacher training would enable more effective evaluation of brain-based claims and facilitate the adoption of tools validated by rigorous independent research rather than programs based on pseudoscience.
\end{abstract}

There is a popular myth among educators that traditional learning favors the left hemisphere (the "academic" brain) and neglects the right hemisphere (the "creative" or "artistic" brain), purportedly leaving half a student's brain undereducated (e.g., Organisation for Economic Co-operation and Development, 2007). Reasoning that student learning will be enhanced by targeting the overlooked "right brain" (and/or adopting "whole-brain" techniques), a variety of educational theories, tools, and systems have been introduced (e.g., Brain Gym, Shichida Method; Petty, 2004). Across Southeast Asia over 400 "Mind Research Consultant" kindergartens

${ }^{1}$ School of Psychological Science, La Trobe University

${ }^{2}$ School of Psychological Sciences, The University of Manchester

Address correspondence to Annukka K. Lindell, School of Psychological Science, La Trobe University, Bundoora, VIC 3086, Australia; e-mail: a.lindell@latrobe.edu.au. proudly boast their use of "innovative right-brain learning methods" (http://rightbrainteaching.com/). There are DVDs for "Teaching the Right-Brain Child" and "Right-Brain Math," books entitled "Teaching for the Two-sided Mind" (Williams, 1986) and "Right-brained Children in a Left-brained World" (Freed \& Parsons, 1998), and even Nintendo DS games purporting to train the left and right hemispheres ("Left Brain, Right Brain", 2007). All of these materials and methods imply a basis on sound scientific theory-the problem is that there is no evidence to suggest (1) that traditional teaching neglects the right hemisphere, (2) that people favor one side of the brain, or (3) that any educational tool or strategy can selectively activate one hemisphere.

Educators are keen to ensure that the learning strategies used in the classroom are effective in shaping children's brain and cognitive development. At present, however, there is a dearth of research that directly addresses the relationship between neuropsychological strengths and weaknesses and learning (Immordino-Yang, 2007). Given this lack of directly relevant research, educational consultants and marketersmost of whom lack neuroscientific expertise-have overgeneralized and/or oversimplified distantly related neuroscientific research, with the end result that educators and educational institutions are being encouraged to adopt "brain-based" programs, unaware of the fact that these programs are pseudoscientific. A number of unscientific "brain-based" ideas have consequently become well-established in classroom, including the notion that students can (and should) be categorized according to their hemispheric dominance (i.e., whether they are "left-brained" or "right-brained"; Howard-Jones, 2009).

The ideas that people are "left-" or "right-brained", or that an educational program could selectively stimulate one or the other side of the brain, may appear appealingly simple; it is this appealing simplicity that has led to their neuromyth status 
(popular but false beliefs about the brain). This article systematically challenges the scientific validity of "left-brain/rightbrain" teaching methods, explaining why educational tools/strategies that make "left-brain/right-brain" claims are fundamentally flawed. It is divided into five sections: first we explain the idea of hemisphericity and the tendency to ascribe opposing functions to the left and right sides of the brain. We then examine some of the major challenges to the validity of "right-brain" teaching, focusing on (1) difficulties in inferring from the split brain to the normal brain, (2) research indicating that the right hemisphere is not the "creative" hemisphere, and (3) the implications of neurological development and brain plasticity. We then discuss the dangerous appeal of neuromarketing, highlighting the influence of brain-based names on perceived scientific merit, before detailing a number of recommendations that will assist educators in effectively evaluating the claims of such brain-based methods. As will become clear, the idea that a teaching program or educational tool could selectively stimulate one side of the human brain is half-witted.

\section{HEMISPHERICITY}

The notion that human cognitive functions are neatly lateralized to either the left or right hemisphere was prompted by the fact that the human brain is divided into two halves. This conspicuous division of the brain into two sides, a left and a right, has encouraged researchers and theorists to propose that the functions of the two hemispheres are polar opposites: "if one hemisphere is known to act in a particular way, the other hemisphere must do the opposite", (Bryden, 1982, p. 4). Numerous descriptions contrasting the functions or processing styles of the left and right hemispheres have been proposed over the past 2500 years, with Bryden and Allard (1981) coining the term "dichotomania" to describe our penchant for ascribing faculties to one or the other side of the brain. The left hemisphere is typically characterized as verbal, rational, logical, and analytic, whereas the right hemisphere is thought to be visuospatial, emotional, and creative (see Van Lancker, 1997). In sum, the right hemisphere's creativity is contrasted with the left hemisphere's sensibility: "the left brain is more logical and linear ... responsible for the brain's thinking functions, which are comparatively more critical and analytical," whereas the right hemisphere "allows us to make insightful connections and see relationships between pieces of information" (Parry \& Gregory, 2006, p. 9).

Ideas about the left and right hemispheres' processing strengths have prompted left and right-brain theorists to propose that people can be similarly classified according to their "hemisphericity" (i.e., left vs. right-brain thinking and behavioral style, Bogen, DeZure, TenHouten, \& Marsh, 1972): "left-brain" people are verbal, analytical, and logical, whereas "right brain" people are artistic, creative, and emotive (e.g.,
Sousa, 1995). Though such a division appears appealingly simple, differences in people's verbal or creative abilities are not linked to differences in left versus right hemisphere processing; the idea that people are "left-brained" or "rightbrained" is not supported by neuroscientific research. All people, from the most logical and analytic to the most emotional and creative, use both hemispheres of the brain simultaneously when performing any task. The suggestion that someone is "right-brained" because they are particularly creative, or "left-brained" because they are analytic and scientific, is a nonsense (Corballis, 1980). The idea of hemisphericity was consequently debunked in the scientific literature in the 1980s, with Beaumont, Young, and McManus (1984) concluding that "... the idea of hemisphericity lacks adequate foundation ... (and) is a misleading one which should be abandoned", (p. 191). Despite this, educators and educational bodies are still investing valuable time and money on resources and strategies based on hemisphericity. Indeed, a Google search of "right-brain teaching" yields 1,730,000 hits. As Bruer (2008) notes " 'Right brain versus left brain' is one of those popular ideas that will not die," (p. 54). Though "right-brain teaching" is a scientifically unfounded neuromyth, it has unfortunately shaped the way school curricula are developed and taught (Neuroscience Research in Education Summit, 2009).

\section{PROBLEMS IN INFERRING FROM SPLIT-BRAIN RESEARCH}

Characterization of the left hemisphere as logical, intelligent, and analytic and the right hemisphere as creative, emotional, and visuospatial was catalyzed by Sperry's (1961) research on split-brain patients. The split-brain operation is performed as a last resort to relieve intractable epilepsy in patients whose seizures prove unresponsive to pharmaceutical intervention. The procedure limits the spread of seizure activity from one hemisphere to the other by severing the corpus callosum (Bogen, Fisher, \& Vogel, 1965). The corpus callosum is a band of 250,000,000 nerve fibers that connects the left and right sides of the brain; severing the corpus callosum consequently prevents communication between the two hemispheres, relieving seizure activity. As the split-brain operation functionally isolates the left and right hemispheres, research on split-brain patients affords the opportunity to examine the functions and capabilities of each hemisphere without contribution or inhibition from the opposing hemisphere (Zaidel, 1978). For example, split-brain patients are typically able to verbally name words projected to their left, but not right, hemisphere (e.g., Gazzaniga, 1970), and show a strong right hemisphere superiority for visuospatial tasks such as mental rotation (e.g., Corballis \& Sergent, 1988). It is this kind of research that has prompted theorists to propose that 
the left hemisphere is verbal, logical, and analytic, whereas the right hemisphere is visuospatial, creative, and emotional, with Sperry (1982) himself noting that "the left-right dichotomy ... is an idea with which it is easy to run wild" (p. 1225).

Drawing inferences for the normal brain from the brains of patients who have had their corpus callossa surgically severed is clearly problematic. Split-brain patients suffer sufficiently severe and pharmaceutically intractable seizures to warrant surgical separation of the two sides of their brains; such severe epilepsy is "... virtually certain to have [produced] neurological abnormalities" (Hellige, 1993, p. 13). As such, split-brain patients had atypical brains even before undergoing surgery, making drawing inferences from the split brain to the normal brain doubly challenging. In the normal brain, the left and right hemispheres are heavily interconnected, and constantly in communication. The intact corpus callosum allows information presented to one hemisphere to be shared with the other hemisphere within $20 \mathrm{~ms}$ (i.e., two hundredths of a second; Andreassi, 2007). In split-brain patients such communication is precluded, thus one must be very cautious in generalizing left and right hemisphere processing biases from the split brain to the normal brain.

In the normal child, the intact corpus callosum allows information to be almost instantaneously integrated, and thus processing occurs simultaneously in both sides of the brain: it is not possible for a normal individual to selectively use one hemisphere. Yet, such inferences are the implicit basis for all educational programs, teaching strategies, and books professing to harness or promote the capacities of the right (or left) hemisphere. As Alferink and Farmer-Dougan (2010) state: "It is neither accurate nor realistic to believe that individuals may selectively use one hemisphere of the brain at a time for separate academic functions" (p. 43); the idea that a particular strategy will differentially affect a particular brain hemisphere is thus deeply flawed.

\section{CREATIVITY IS NOT RIGHT LATERALIZED}

According to the left-brain/right-brain view, creativity is one of the key strengths of the right hemisphere that is overlooked in traditional teaching. Accordingly, it is proposed that the right hemisphere's creativity should be targeted with specific teaching methods (e.g., Shichida Method). However, though the notion that the right hemisphere is creative is appealing in its simplicity, the idea that creativity is solely a function of one side of the brain is contentious (see Lindell, 2011, for review). Even language articulation, the most strongly lateralized processes, involves the activation and integration of processes across both sides of the brain (see Lindell, 2006). Similarly, a growing body of research suggests that any creative act relies upon the activation and integration of processing in both hemispheres: "no scientific evidence ... indicates a correlation between the degree of creativity and the activity of the right hemisphere" (Organisation for Economic Cooperation and Development, 2007, p. 117).

Lindell's (2011) review of neuroscience research suggests that creativity is a distributed, whole brain process, rather than solely a function of the right hemisphere. For example, Carlsson, Wendt, and Risberg (2000) reported that during a creative task (come up with alternate uses for a common object), highly creative people showed greater activation across both sides of the brain in comparison to the less creative people. This suggests that the ability to engage both hemispheres leads to the generation of more creative solutions than relying predominantly on one side of the brain. This being the case, one might predict that people engaged in creative professions (e.g., musicians and artists) would show greater interaction between the two sides of the brain than people in non-creative professions. Gibson, Folley, and Park (2009) confirmed this prediction, implying that creative training enhances interhemispheric communication which, in turn, fosters creative ideation and enhanced creative performance. Such findings suggest that the interaction between distant cortical regions across both hemispheres is crucial for creative thinking: "It can't be emphasized too strongly that creativity is best viewed as a whole-brain (rather than a right-brain) process" (Runco, 2004, p. 665)

The research evidence clearly indicates that the interaction between the left and right hemispheres is vital for creativity, rather than the actions of one hemisphere alone. Educational tools claiming to selectively stimulate the right hemisphere to enhance creativity (e.g., Shichida Method; Edwards, 2001) are thus ill-founded. Even if such methods were capable of selectively stimulating the right hemisphere (as discussed above, this is impossible in the normal brain), the scientific research indicates that selective stimulation of the right hemisphere would not enhance creativity because creativity is a whole-brain process. As such, educational tools promising a "right-brained" approach to enhance creativity are scientifically baseless.

\section{NEUROLOGICAL DEVELOPMENT AND BRAIN PLASTICITY}

Strictly dichotomizing brain function is even more problematic when one considers brain development. Developmental studies of brain function have consistently shown that while brain regions are predisposed to process certain types of input, localization of higher cognitive functions into one hemisphere is not present at birth, and nor is it deterministic. We illustrate this point by discussing the localization of language - a paradigm case of lateralization of function.

The neuroscientific study of language is centuries old. Popular interpretations of this field of research have led 
those outside of the immediate research field to believe that language is largely a left hemisphere function. This is hardly surprising: early case studies reported by Broca (1861) and Wernicke (1911) showed that patients who had significant damage to parts of their left cerebral cortex had compromised language function. Specifically, those with damage in what came to be known as Broca's area (inferior frontal gyrus) experience problems with language production, whereas those with damage to Wernicke's area (superior temporal gyrus) experience language comprehension difficulties. Language is the crowning achievement of our species (Tomasello, 2008); it is a complex analytic system that currently defies neat explanation by cognitive scientists of all theoretical persuasions (see Evans \& Levinson, 2009), and yet children have the capability to learn any language with apparent ease. Language is also the dominant symbolic system of our culture, and is prioritized over other forms of communication (e.g., art). Thus it is not surprising that the left hemisphere has been popularized as "analytic" or "academic", and that those concerned with education might believe that traditional educational practices prioritize these skills.

However, now there exists a host of evidence to show that (1) language is not strictly localized in the left hemisphere, (2) language only gradually lateralizes in the left hemisphere during development, and (c) damage to areas that are traditionally recruited for language in children results in the recruitment of alternative brain regions, including the right hemisphere, to support the language learning process. We discuss each of these points briefly.

Advances in non-invasive neuroimaging techniques have enabled an increasingly sophisticated insight into human brain function and its development. With respect to language, an increasing amount of evidence has accumulated to suggest that the right hemisphere is implicated in many aspects of language processing (for review see Lindell, 2006), and that each hemisphere only comes to support different language functions across development. For instance, in one of the most comprehensive neurodevelopmental studies of language development, Szaflarski et al. (2006) followed 30 children aged 5-7 years longitudinally for 5 years. The children were scanned using functional Magnetic Resonance Imaging once a year on a task that measured their language processing ability. The results showed that, consistent with similar cross-sectional studies (Holland et al., 2001), there is increasing lateralization of language with age, where areas in the left hemisphere that appear to be predisposed to support language become increasingly involved in language processing over developmental time. Ressel, Wilke, Lidzba, Lutsenberger, and Krägeloh-Mann (2008) have reported similar results using magnetoencephalography, a newer and more fine-grained imaging technique.

These imaging results show that there are qualitative changes in the brain areas that are used to support language function across development, which in the normal case lead to mostly left hemisphere lateralization accompanied by some right hemisphere involvement. However, what happens when those left hemisphere areas predisposed for language function become damaged? The data suggest that, far from being the end of language, the brain is plastic enough in development to reorganize the neural circuits that process language. For instance, work by Bates and colleagues (e.g., Bates et al., 1997; Bates, Vicari, \& Trauner, 1999; Vicari et al., 2000) has shown that young children with focal brain damage to their left hemisphere are able to recruit alternative neural areas to continue the language acquisition process. In cases where brain damage occurs early in life ( $\leq 6$ months), these early deficits are no longer detectable at the behavioral level by about 7 years-of-age (e.g., Marchman, Saccuman, \& Wulfeck, 2004; Reilly, Losh, Belugi, \& Wulfeck, 2004). This suggests two important points: (l) even a highly analytical skill like language is more bilaterally represented in childhood, and (2) the developing brain has the potential for great plasticity, and is able to reorganize important higher cognitive functions in the event of major neurological trauma. In fact, damage to the left cerebral hemisphere early in development seems to result in the right lateralization of language (Staudt et al., 2001).

By reviewing the literature on language lateralization and plasticity we make the following points. First, it does not make sense for any cognitive function to be partitioned and deterministically localized in one hemisphere, even language, which is an analytical skill par excellence. Instead, we argue that interaction is the norm for brain function, rendering claims about educational tools targeting the right or left hemisphere difficult to defend. Second, the bilateral processing of higher cognitive skills such as language and the ability for the developing brain to recruit alternative neural pathways in the event of significant neurological insult renders any claims for dichotomous brain function baseless. The complexity of neurological development is not captured by pseudoscientific educational products that imply a strict and direct relationship between brain and behavior. Any attempt to incorporate recent developments in the study of neurological development into these approaches would fail, since their principal claim is that there are simple hemisphere-to-function relationships that can be individually targeted using educational tools.

\section{OVERCOMING THE DANGEROUS APPEAL OF NEUROMARKETING: RECOMMENDATIONS}

Consumers in the market for educational programs are faced with a wide variety of choices. In such a market, claims that a particular tool or learning strategy is "brain-based", selectively stimulating the "overlooked right hemisphere" have inherent appeal; every educator wants to positively influence the learning child's brain. The difficulty here is that consumers are often poorly equipped to objectively evaluate the scientific claims made by "brain-based" educational packages. The 
inclusion of "neuro" information (either brain images or accurate but irrelevant neuroscience information) positively influences people's ratings of an article's scientific merit (e.g., McCabe \& Castel, 2008; Weisberg, Keil, Goodstein, Rawson, $\&$ Gray, 2008), a fact that helps explain the popularity of neuromarketing approaches in education. The simple use of the word "brain" in the title of an educational tool or theory suggests a sound scientific foundation, irrespective of the validity of the "brain" claims. Given that almost $90 \%$ of teachers believe that knowledge of the brain is important in informing the design of educational programs (Della Sala, 2009), strategic use of the word "brain" in the name can profoundly influence of the adoption of an educational tool.

Educators thus need to become more critical consumers and interpret brain-based claims cautiously (see Sylvan \& Christodoulou, 2010), and teacher training must equip educators with the tools needed to effectively evaluate neuroscience-based programes. At present, teacher training offers little exposure to primary source neuroscience research, instead focusing predominantly on summaries and popular press interpretations (Coch \& Ansari, 2009). This lack of information makes teachers a soft target for peddlers of pseudoscience. Providing teachers with a basic understanding of neuroscience research and neuroscientific methods as part of teacher training is vital as it enables teachers to understand how learning occurs in the brain, and how cognitive abilities change in the course of brain development (Goswami, 2004). Moreover, a foundational understanding of neuroscience will enable educators to effectively evaluate "brain-based" claims and seek out educational tools using methods that have been validated by rigorous independent research.

A basic education in neuroscience need not be an onerous component of initial teacher education. If the information is presented in a straightforward manner using understandable terms and concrete examples, student teachers could receive a primer on the essentials of neuroscience, brain development, and cognitive processing in a day. Based on such a foundation, these concepts could be revisited and further developed throughout teacher training (e.g., attention, memory, mnemonics), making basic brain understanding an integral and integrated part of the course. Such understanding is likely to enhance student learning and help prevent future educators from "pouring precious educational resources into scientifically spurious applications" (Goswami, 2006, p. 413), allowing them to more critically evaluate the validity of the $70+$ brain-based learning courses many are invited to each year (Goswami, 2006).

As Jorgenson (2003) points out, "brain-based" educational tools are typically researched, developed, and promoted by educational and marketing consultants, few of whom have expertise in neuroscience. Little wonder then that neuroscience research is overgeneralized, oversimplified, or misinterpreted in the quest for appealing new educational programes (e.g., Brain Gym, Dore program; Della Sala, 2009). Though brain-based education marketers "spin stories about how brain research, as they understand it, supports their favorite educational practices, none of these educational applications is supported by data showing either that it produces the desired change in brain structure or that such changes affect behavior and learning" (Bruer, 2002, p. 1031). The fact that the brain-based programes are not presented or advertized in concert with research confirming that they genuinely induce changes in brain activation and student learning efficacy immediately calls the validity of such programs into question. And indeed, a search of scientific databases like Medline and PsychInfo confirms that there is no published research on the application of neuroscience to education (Bruer, 2002). ${ }^{1}$

We encourage teachers to ask one simple question when presented with a brain-based learning programe: (1) have the brain-based claims been validated by independent research that confirms that the tool or strategy genuinely induces changes in brain activation and student learning efficacy? If the answer is "yes" and the research is available for scrutiny in a reputable journal, the tool is worthy of consideration. If the answer is "no" and the brain-based claims are being presented solely by someone who stands to financially gain from adoption of the tool, the tool should be summarily rejected.

There is no question that neuroscience has the potential to make powerful contributions to educational research; however, stronger links between neuroscience and basic research in education are needed to fulfill this potential (Goswami, 2004). Greater communication between educationalists and neuroscientists would ensure that (1) neuroscientists are studying the educational questions that are of real importance to teachers, and (2) educationalists understand both the strengths and the limitations of neuroscientific approaches to teaching and learning. Critical to such a dialogue is the need for more efficient dissemination of appropriately targeted accounts of relevant neuroscience findings. The introduction of targeted journals and conferences is a promising step (e.g., Mind, Brain, and Education); however whether the majority of teachers, old or new, have the luxury of time needed to peruse such documents or attend such events is an open question. Moreover, whether neuroscientists themselves are best-equipped to communicate directly with educators has been questioned. Goswami (2006) suggests that a network of research communicators may be better placed to interpret and communicate neuroscience findings in the language of educators, and to feedback questions, ideas, and criticisms to the neuroscientists. We agree that such a network of science communicators would be invaluable in enhancing neuroscience understanding and restricting the pervasiveness of neuromyths. Communication would be further enhanced by the introduction of a regular, interactive e-mail/online "digest" of Neuroscience Education News that presents an accurate 
summary of the latest findings relevant to the teacher in the classroom. Such dissemination of information will greatly assist educationalists in discerning neuroscience fact from neuroscience fiction.

\section{CONCLUSIONS}

The idea that the functions of the brain's hemispheres could be straightforwardly divided into left and right, though appealingly simple, is patently false. Similarly, the notion that a person can be classified as "left-brained" or "rightbrained," or that a teaching strategy could selectively target the left or right hemisphere, is deeply flawed and is not supported by the research. The idea that the left hemisphere is logical, verbal, and analytic, whereas the right hemisphere is creative, emotive, and visuospatial was catalyzed by Sperry's (1981) split-brain research. As discussed, drawing inferences for normal children's brains from the brains of patients who have had sufficiently severe epilepsy to warrant the surgical separation of their left and right hemispheres is extremely problematic. Similarly, the idea that selective stimulation of the right hemisphere will enhance children's creativity is not consistent with the research evidence (Lindell, in press). Little wonder then that the idea of "hemisphericity" was debunked in the scientific literature over 25 years ago (Beaumont et al., 1984). It is unfortunate that despite the absence of scientific support, educational tools based on such neuromyths are shaping the way children are taught (Neuroscience Research in Education Summit, 2009).

As Chabris and Kosslyn (1998) note, it is highly improbable that any lesson, no matter how visuospatial or analytic, will activate only one hemisphere. When performing any task "everything in the brain (is) in flux-both sides, the front and back, the top and bottom ... to think that you could reduce this to a simple left-right dichotomy would be misleading and oversimplified" (Mazziotta in McKean, 1985, p. 38). Consequently, educational programes that claim to selectively target the right hemisphere (e.g., Craft's "Teaching the RightBrain Child") or ensure that both hemispheres are involved in learning (e.g., Sousa, 1995), are misleading; both hemispheres of the brain are simultaneously activated and constantly interacting and integrating information during every task, including those proposed to activate solely one hemisphere. The use of terms such as "brain" and "neuroscience" in the name and marketing of a product profoundly enhance perceptions of that product's scientific merit, irrespective of the validity of the scientific claims. Educators and educational institutions must therefore interpret neuro-claims cautiously, and seek out methods that have been validated by rigorous independent research. Until the claims of the "right brain" teaching methods have been independently validated, adopting a "right-brain" teaching program would be half-witted.

\section{NOTE}

1 Note that there are educational training products that have been empirically supported, but do not make claims about neurological development. For instance, Holmes, Gathercole, and Dunning (2009) and St Claire-Thompson, Stevens, Hunt, and Bolder (2010) have both tested products that improve children's working memory. Our suggestion here is it is not the marketing spin, but the outcome of the training that matters, which can only ever be shown through carefully controlled empirical research.

\section{REFERENCES}

Alferink, L. A., \& Farmer-Dougan, V. (2010). Brain-(not) based education: Dangers of misunderstanding and misapplication of neuroscience research. Exceptionality, 18, 42-52.

Andreassi, J. L. (2007). Psychophysiology: Human behavior and physiological response. Hillsdale, NJ: Erlbaum.

Bates, E., Thal, D., Aram, D., Eisele, J., Nass, R., \& Trauner, D. (1997). From first words to grammar in children with focal brain injury. Developmental Neuropsychology, 13, 275-343.

Bates, E., Vicari, S., \& Trauner, D. (1999). Neural mediation of language development: Perspective from lesion studies on infants and children. In H. Tager-Flusberg (Ed.), Neurodevelopmental disorders (pp. 533-581). Cambridge, MA: MIT Press

Beaumont, G., Young, A., \& McManus, I. C. (1984). Hemisphericity: A critical review. Cognitive Neuropsychology, 1, 191-212.

Bogen, J. E., DeZure, R., TenHouten, N., \& Marsh, J. (1972). The other side of the brain IV: The A/P ratio. Bulletin of the Los Angeles Neurological Society, 37, 49-61.

Bogen, J. E., Fisher, E. D., \& Vogel, P. J. (1965). Cerebral commisurotomy: A second case report. Journal of the American Medical Association, 194, 1328-1329.

Broca, P. (1861). Remarques sur le siege de la faculte du langage articule; suivies d'une observation d'aphemie. Bulletin de la Société Anatomique, 6, 398-407.

Bruer, J. T. (2002). Avoiding the pediatrician's error: How neuroscientists can help educators (and themselves). Nature Neuroscience (Supplement), 5, 1031-1033.

Bruer, J. T. (2008). In search of ... brain-based education. In The Jossey-Bassreader on the brainandlearning (pp. 51-69). San Francisco: Wiley.

Bryden, M. P. (1982). Laterality: Functional asymmetry in the intact brain. New York: Academic Press.

Bryden, M. P., \& Allard, F. A. (1981). Shortcomings of the verbal-nonverbal dichotomy: Seems to us we've heard this song before. Behavioral and Brain Sciences, 4(1), 65-66.

Carlsson, I., Wendt, P. E., \& Risberg, J. (2000). On the neurobiology of creativity: Differences in frontal activity between high and low creative subjects. Neuropsychologia, 38, 873-885.

Chabris, C.F., \& Kosslyn, S. M. (1998). How do the cerebral hemispheres contribute to encoding spatial relations? Current Directions in Psychological Sciences, 7, 8-14.

Coch, D., \& Ansari, D. (2009). Thinking about mechanisms is crucial to connecting neuroscience and education. Cortex, 45, 546-547.

Corballis, M. C. (1980). Laterality and myth. American Psychologist, 35, 284-295. 
Corballis, M. C., \& Sergent, J. (1988). Imagery in a commissurotomized patient. Neuropsychologia, 26, 13-26.

Della Sala, S. (2009). The use and misuse of neuroscience in education. Cortex, 45, 443.

Edwards, B. (2001). The new drawing on the right side of the brain (3rd ed.). New York: Putnum.

Evans, N., \& Levinson, S. (2009). The myth of language universals. Behavioral and Brain Sciences, 32, 429-448.

Freed, J., \& Parsons, L. (1998). Right-brained children in a left-brained world: Unlocking the potential of your ADD child. New York: Fireside.

Gazzaniga, M. S. (1970). The bisected brain. New York: AppletonCentury-Crofts.

Gibson, C., Folley, B.S., \& Park, S. (2009). Enhanced divergent thinking and creativity in musicians: A behavioral and nearinfrared spectroscopy study. Brain and Cognition, 69, 162-169.

Goswami, U. (2004). Neuroscience and education. British Journal of Educational Psychology, 74, 1-14.

Goswami, U. (2006). Neuroscience and education: From research to practice? Nature Reviews Neuroscience, 7, 406-413.

Hellige, J. B. (1993). Hemispheric asymmetry: What's right and what's Left. Cambridge, MA: Harvard University Press.

Holland, S., Plante, E., Byars, A., Strawsburg, R., Schmithorst, V., \& Ball, W. Jr. (2001). Normal fMRI brain activation patterns in children performing a verb generation task. Neuroimage, 14, 837-843.

Holmes, J., Gathercole, S. E., \& Dunning, D. L. (2009). Adaptive training leads to sustained enhancement of poor working memory in children. Developmental Science, 12, F9-F15.

Howard-Jones, P. A. (2009). Scepticism is not enough. Cortex, 45, 550-551.

Immordino-Yang, M. H. (2007). A tale of two cases: Lessons for education from the study of two boys living with half their brains. Mind, Brain, and Education, 1, 66-83.

Jorgenson, O. (2003). Brain scam? Why educators should be careful about embracing 'brain research'. The Educational Forum, 67, 364-369.

Lindell, A. K. (2006). In your right mind: Right hemisphere contributions to human language processing and production. Neuropsychology Review, 16, 131-148.

Lindell, A. K. (2011). Lateral thinkers are not so laterally minded: Hemispheric asymmetry, interaction, and creativity. Laterality, 16, 479-498.

Marchman, V., Saccuman, C., \& Wulfeck, B. (2004). Productive use of the English past tense in children with focal brain injury and specific language impairment. Brain and Language, 88, 202-214.

McCabe, D. P., \& Castle, A. D. (2008). Seeing is believing: The effect of brain images on judgments of scientific reasoning. Cognition, $107,343-352$.

McKean, K. (1985). Of two minds: Selling the right brain. Discover, 6(4), 30-4l.

Neuroscience Research in Education Summit: The Promise of Interdisciplinary Partnerships Between Brain Sciences and Education. University of California, Irvine. June 22-24, 2009.

Organisation for Economic Co-operation and Development. (2007). Understanding the brain: The birth of a learning science. Paris: Author.
Parry, T., \& Gregory, G. (2006). Designing brain-compatible learning. Cheltenham, Australia: Hawker Brownlow Education.

Petty, G. (2004). Teaching today: A practical guide. Cheltenham, UK: Nelson Thornes.

Reilly, J., Losh, M., Bellugi, U., \& Wulfeck, B. (2004). Frog, Where are you? Narratives in children with specific language impairment, early focal brain injury and Williams Syndrome. Brain and Language, 88, 229-247.

Ressel, V., Wilke, M., Lidzba, K., Lutzenberger, W., \& KrägelohMann, I. (2008). Increases in language lateralization in normal children as observed using magnetoencephalography. Brain and Language, 106, 167-176.

Runco, M. A. (2004). Creativity. Annual Review of Psychology, 55, 657-687.

Sousa, D. A. (1995). Howthebrainlearns:Aclassroomteacher'sguide. Reston, VA: National Association of Secondary School Principals.

Sperry, R. W. (1961). Cerebral organization and behavior. Science, 133, $1749-1757$.

Sperry, R. W. (1982). Some effects of disconnecting the cerebral hemispheres. Science, 217, 1223-1226.

Staudt, M., Grodd, W., Niemann, G., Wildgruber, D., Erb, M., \& Krăgeloh-Mann, I. (2001). Early left periventricular brain lesions induce hemispheric organization of speech. Neurology, 57, 122-125.

St Claire-Thompson, H., Stevens, R., Hunt, A., \& Bolder, E. (2010). Improving children's working memory and classroom performance. Educational Psychology, 30, 203-219.

Sylvan, L. J., \& Christodoulou, J. A. (2010). Understanding the role of neuroscience in brain based products: A guide for educators and consumers. Mind, Brain, and Education, 4, 1-7.

Szaflarski, J., Schmithorst, V., Altaye, M., Byars, A., Ret, J., Plante, E., et al. (2006). A longitudinal functional magnetic resonance imaging study of language development in children 5 to 11 years old. Annals of Neurology, 59, 796-807.

Tomasello, M. (2008). Origins of human communication. Cambridge, MA: MIT Press.

Van Lancker, D. (1997). Rags to riches: Our increasing appreciation of cognitive and communicative abilities of the human right cerebral hemisphere. Brain and Language, 57, 1-11.

Vicari, S., Albertoni, A., Chilosi, A., Cipriani, P., Cioni, G., \& Bates, E. (2000). Plasticity and reorganization during language development in children with early brain injury. Cortex, 36, 31-36.

Weisberg, D. S., Keil, F. C., Goodstein, J., Rawson, E., \& Gray, J. R. (2008). The seductive allure of neuroscience explanations. Journal of Cognitive Neuroscience, 20, 470-477.

Wernicke, C. (1911). The symptom of complex aphasia. In. A. E. Church (Ed.), Diseases of the nervous system (pp. 265-324). New York: Appleton.

Williams, L. V. (1986). Teaching for the two-sided mind: A guide to right brain/left brain education. New York: Simon \& Schuster.

Zaidel, E. (1978). Lexical organization in the right hemisphere. In P. A. Buser \& A. Rougeul-Buser (Eds.), Cerebral correlates of conscious experience. Amsterdam: Elsevier. 